\title{
Surgical Management of Subclavian and Proximal Axillary Artery Injuries
}

\author{
Zia Ur Rehman, Suleman Yousaf and Tehmeed Ahmad \\ Section of Vascular Surgery, Department of Surgery, The Aga Khan University Hospital, Karachi, Pakistan
}

\begin{abstract}
Subclavian and proximal axillary arterial injuries are rare and difficult to manage. Eight patients were managed from January 2008 to December 2018 at The Aga Khan University Hospital, Karachi, Pakistan with mean age of $36.13 \pm 14.48$ years. All patients had penetrating injuries, from gunshot in $5(62.5 \%)$, bomb blast in $2(25 \%)$, and stab wound in $1(12.5 \%)$ case. Six $(75 \%)$ patients presented in haemodynamically stable condition. The mean time between the injury and patient presentation was $28 \pm 8.39$ hours. The injuries were approached via supraclavicular incision in $3(37.5 \%)$ patients, infraclavicular incisions in $2(25 \%)$ patients and median sternotomy in $2(25 \%)$ patients. Three $(37.5 \%)$ patients had false aneurysm, while $5(62.5 \%)$ had transected artery. Primary repair was performed in $2(25 \%)$ cases, while $6(75 \%)$ patients were treated with interposition graft with polytetrafluoroethylene (PTFE). All patients have salvaged limbs with good functional outcomes.
\end{abstract}

Key Words: Subclavian artery, Penetrating injury, Vascular trauma, Vascular repair.

How to cite this article: Rehman ZU, Yousaf S, Ahmad T. Surgical Management of Subclavian and Proximal Axillary Artery Injuries. J Coll Physicians Surg Pak 2021; 31(12):1513-1515.

Penetrating subclavian artery injuries occur infrequently and constituteless than $2 \%$ of all civilian vasculartraumas. ${ }^{1}$ Subclavian and axillary vascular injuries are notorious for their mortality. This is related to difficult surgical exposure and complex local anatomy. Subclavian and axillary arteries are well protected by bony structures at the thoracic outlet; and the challenge is to achieve proximal and distal control quickly for these vessels, which requires extensive dissection involving median sternotomy, supra- and infra-clavicular incisions or thoracotomy. Brachial plexus and surrounding structures are at risk of this dissection. With loss of proximal control, patients can succumb to death. Very few surgeons have adequate training and experience to deal these rare injuries; and even the exposure of these arterial injuries may challenge the most experienced trauma surgeons. The operative mortality of these injuries ranges from $5 \%$ to $30 \%$ and attributed to rapid exsanguination and a high incidence of concomitant injuries. $^{2}$

The objective of this study is to review the clinical presentations, treatment options and outcomes of the subclavian and proximal axillary artery injuries, managed at a university hospital.

Correspondence to: Dr. Zia Ur Rehman, Section of Vascular Surgery, Department of Surgery, The Aga Khan University Hospital, Karachi, Pakistan

E-mail: ziaur.rehman@aku.edu

Received: July 14, 2021; Revised: September 16, 2021;

Accepted: October 04, 2021

DOI: https://doi.org/10.29271/jcpsp.2021.12.1513
It was a retrospective review of the medical records of all patients with subclavian and proximal axillary arteries injuries, who were surgically managed at The Aga Khan University Hospital, Karachi during the last 10 years from January 2008 to December 2018. The operative strategy for proximal control of right subclavian artery was median sternotomy; and distal control by infra-clavicular approach. For left subclavian artery injury, the preferred approach for proximal control was leftanterior thoracotomy; and distal control was achieved by infra-clavicular approach. Combined supra- and infra-clavicular incisions were used to gain proximal and distal control of proximal axillary artery. After achieving proximal and distal control, injured vessel was defined and debrided till healthy edges. Vessel was repaired either primarily or with an interposition vein or PTFE graft. Blood flow restored and patients observed for any postoperative complications, such as graft thrombosis or bleeding, requiring intervention.

During the study duration, eight patients were managed for these injuries. Perioperative patients' characteristics and outcomes are given in Table I. The mean age of these patients being $36.13 \pm 14.48$ years. All had penetrating injuries: gunshot $5(62.5 \%)$, bomb blast $2(25 \%)$, and $1(12.5 \%)$ stab wound. Two patients $(25 \%)$ presented with hypotension. The mean time between the injury and patient presentation was $28 \pm 8.39$ hours. All patients presented with active bleeding. Two (25\%) patients had left sided pneumothorax and other two (25\%) patients had neck swelling.

These injuries were approached via supra-clavicular incisions in $3(37.5 \%)$ patients, infra-clavicular incisions in $2(25 \%)$ patients and median sternotomy in 2 (25\%) patients. 
Table I: Perioperative patients' characteristics and outcomes.

\begin{tabular}{|c|c|c|c|c|c|c|c|c|c|c|c|}
\hline Patient & Age & Gender & BP at arrival & $\begin{array}{l}\text { Presented } \\
\text { to hospital }\end{array}$ & $\begin{array}{l}\text { Mechanism } \\
\text { of injury }\end{array}$ & $\begin{array}{l}\text { CTA done } \\
\text { on arrival }\end{array}$ & $\begin{array}{l}\text { Method of } \\
\text { surgical } \\
\text { approach }\end{array}$ & Pathology & Reconstruction & $\begin{array}{c}\text { Additional } \\
\text { injuries/ } \\
\text { procedures }\end{array}$ & $\begin{array}{c}\text { Outcomes } \\
\text { limb } \\
\text { salvaged }\end{array}$ \\
\hline 1 & 22 & M & $121 / 71$ & $<24$ hours & Gunshot injury & No & $\begin{array}{c}\text { Supraclavicular } \\
\text { incision only }\end{array}$ & - & $\begin{array}{l}\text { Interposition } \\
\text { grafting }\end{array}$ & - & Y \\
\hline 2 & 52 & $\mathrm{~F}$ & $131 / 79$ & $<24-48$ & Bomb blast & No & Median sternotomy & - & Primary repair & Fracture of $1^{\text {st }}$ rib & $Y$ \\
\hline 3 & 25 & M & $120 / 70$ & $>48$ & Stab & Yes & $\begin{array}{l}\text { Infraclavicular } \\
\text { incision only }\end{array}$ & - & $\begin{array}{l}\text { Interposition } \\
\text { grafting }\end{array}$ & Brachial A injury & Y \\
\hline 4 & 42 & M & $80 / 45$ & $>24$ & Gunshot injury & Yes & $\begin{array}{c}\text { Infraclavicular } \\
\text { incision only }\end{array}$ & - & Interposition graft & Brachial A injury & Y \\
\hline 5 & 65 & M & $154 / 92$ & $<24$ & Gunshot injury & No & Median sternotomy & $\begin{array}{c}\text { False } \\
\text { aneurysm }\end{array}$ & Primary repair & $\begin{array}{c}\text { Head Injury } \\
\text { axillary vein injury }\end{array}$ & $Y$ \\
\hline 6 & 30 & M & $40 / 42$ & $<24$ & Gunshot injury & No & $\begin{array}{l}\text { Supraclavicular } \\
\text { incision only }\end{array}$ & - & $\begin{array}{l}\text { Interposition } \\
\text { grafting }\end{array}$ & $\begin{array}{c}\text { Hemidiaphragm } \\
\text { rupture }+ \text { splenic } \\
\text { tear }\end{array}$ & Y \\
\hline 7 & 24 & $M$ & $100 / 65$ & $<24$ & Gunshot injury & Yes & $\begin{array}{l}\text { Supraclavicular } \\
\text { incision only }\end{array}$ & $\begin{array}{c}\text { False } \\
\text { aneurysm }\end{array}$ & $\begin{array}{l}\text { Interposition } \\
\text { grafting }\end{array}$ & Clavicular fracture & $Y$ \\
\hline 8 & 29 & M & $99 / 59$ & $<24$ & Bomb blast & Yes & $\begin{array}{c}\text { Supraclavicular } \\
\text { incision }\end{array}$ & $\begin{array}{c}\text { False } \\
\text { aneurysm }\end{array}$ & Primary repair & & Y \\
\hline
\end{tabular}

Three patients had false aneurysm, while others had transected artery. Primary repair was performed in 2 (25\%) cases, while $6(75 \%)$ patients were treated with interposition graft with PTFE. Two patients (25\%) had also concomitant brachial artery injuries and underwent brachial artery exploration. One $(12.5 \%)$ patient had ruptured left hemi-diaphragm and ruptured spleen.

All patients' limbs were salvaged with good functional outcomes; and were followed for immediate postoperative period for at least 30 days.

Trauma to subclavian and axillary arteries poses a unique challenge in part due to proximal anatomical structures; and in part, due to difficult vessel exposures. ${ }^{5}$ This case series showed that patients presenting to a trauma centre in a low-to-middle income country with subclavian and axillary artery injuries were young, had penetrating injuries and were haemodynamically stable. All patients presented with active bleeding. Repair with interposition PTFE grafting was the most common treatment strategy. Multiple approaches were used to access and deal these injuries. Limb salvage rate was $100 \%$.

The incidence of subclavian artery injuries remains unclear. Kou et al. found the incidence rate of subclavian injuries to be $0.05 \%$ in all trauma hospitalised patients. ${ }^{3}$ The clinical diagnosis of subclavian injury is still challenging because of various presentations. The most frequent manifestation is the ischemia, resulting from arterial occlusion, such as diminished or absent pulses in the upper arm. Gill et al. surgically managed 68 patients with axillary artery after penetrating trauma. They performed primary repair in $60 \%$ of the patients; and performed ligation as a life-saving maneuver for critically ill patients. They also noted associated brachial plexus injury as cause of long-term morbidity. ${ }^{4}$ Aksoy et al. managed 38 patients subclavian-axillary artery injuries over 13 years surgically; and found surgical revascularisation effective in salvaging the limbs. They also found that final functional outcome of limbs depends on associated neurological, orthopaedic and soft tissue injuries. The surgical approach described by them is almost like ours. ${ }^{5}$ Endovascular methods offer an alternative to these injuries. Xenos et al. described seven patients managed with these injuries using Wallstent endoprosthesis. They also did comparative analysis with cohort of patients managed surgically during the same time duration. They noted that endovascular intervention was associated with shorter operative time $(p=0.04)$ and less blood loss $(p=0.01)$, compared to surgical managed patients. One-year patency was similar in both surgical and endovascular group. They concluded that covered stents are a feasible alternative to open repair in properly selected patients. ${ }^{6}$ Over the last two decades, endovascular technique and experience have matured, but surgery remains effective and practical treatment options in centres where endovascular facilities are lacking or still developing.

Management of the concomitant subclavian and brachial artery injury is challenging. The hand is more ischemic in case of both injuries than in patients with isolated brachial or subclavian artery injuries and warrants urgent revascularisation. Both injuries need to be treated to maintain good inflow and outflow. The approach was to repair subclavian and axillary arteries followed by brachial artery in the same setting.

Limitations of this study include a retrospective design with limited number of patients and from a single centre. It missed the patients who did not reach hospital. This does not represent the true spectrum of subclavian and axillary artery injuries.

These findings can help improve the quality of care in patients receiving treatment for axillary and subclavian artery injuries in Pakistan and abroad.

\section{CONFLICT OF INTEREST:}

The authors declared no conflict of interest.

\section{AUTHORS' CONTRIBUTION:}

ZUR: Study design, data collection, data analysis, writing $1^{\text {st }}$ draft, critical analysis and revision, literature review, approval of final draft, and responsibility of all aspects of work. 
SY, TA: Data collection, data analysis, approval of final draft, and responsibility of all aspects of work.

\section{REFERENCES}

1. Wall MJ, Granchi T, Liscum K, Mattox KL. Penetrating thoracic vascular injuries. Surg Clin North Am 1996; 76(4): 749-61. doi: 10.1016/s0039-6109(05)70478-3.

2. Kalakuntla V, Patel V, Tagoe A, Weaver W. Six-year experience with management of subcalvian artery injuries. Am Surg 2000; 66(10):927-31.

3. Kou HW, Liao $\mathrm{CH}$, Huang JF, Hsu CP, Wang SY, Ou Yang CH, et al. Eighteen years' experience of traumatic subclavian vascular injury in a tertiary referral trauma center. Eur J Trauma Emerg Surg 2019; 45(6):973-8. doi: 10.1007/ s00068-018-01070-5.

4. Gill H, Jenkins W, Edu S, Bekker W, Nicol AJ, Navsaria PH. Civilian penetrating axillary artery injuries. World J Surg 2011; 35(5):962-6. doi: 10.1007/s00268-011-1008-8.

5. Aksoy M, Tunca F, Yanar H, Guloglu R, Ertekin C, Kurtoglu M. Traumatic injuries to the subclavian and axillary arteries: $A$ 13-year review. Surg Today 2005; 35(7):561-5. doi: 10.1007/s00595-005-2990-y.

6. Xenos ES, Freeman M, Stevens S, Cassada D, Pacanowski J, Goldman M. Covered stents for injuries of subclavian and axillary arteries. J Vasc Surg 2003; 38(3):451-4. doi: 10.1016/s0741-5214(03)00553-6. 